International Journal of Instruction e-ISSN: 1308-1470 • www.e-iji.net

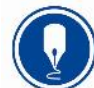

October $2021 \bullet$ Vol.14, No.4

p-ISSN: 1694-609X

pp. 21-32

Article submission code:

20200725124746

Received: $25 / 07 / 2020$

Revision: 16/02/2021

Accepted: 12/03/2021

OnlineFirst: 05/07/2021

\title{
A Collaborative Teacher Training Approach in Different Cultures in the Era of Technology
}

\section{Ali Usman Hali}

School of Education, Shaanxi Normal University, Xi'an, China, aliusmanhali@outlook.com

\section{Baohui Zhang}

Corresponding author, School of Education, Shaanxi Normal University, Xi'an, China, baohui.zhang@snnu.edu.cn

$\begin{aligned} & \text { Abdo Hasan Al-Qadri } \\ & \text { School of Education, Shaanxi Normal } \\ & \text { abdoalqadri@ outlook.com }\end{aligned}$
$\begin{aligned} & \text { Sarfraz Aslam } \\ & \begin{array}{l}\text { School of Education, } \\ \text { sarfrazmian@nenu.edu.cn }\end{array}\end{aligned}$

Teacher training has entered the collaborative phase as faculty members from different universities worldwide have been sharing their teaching practices using the available educational technologies. This has made curriculum development more exciting and the ideas more diverse since other cultures may have different approaches to tackling subjects taken up in the curriculum. This study used a qualitative case study approach since it wanted to show a broader picture of the learning experiences; mainly, this study included ten professors and students from three universities and used collaborative teaching to show how a project can be achieved by different parties collaborating. This study investigated the online educational courses that have capitalized on the available educational technologies to show diversity in their curriculum. The researcher also conducted class observations where the students explored collaborative teaching methods across different cultures and compared their similarities and differences. The study also assessed how educational technology has helped achieve diversity in curriculum development as professors from different universities worldwide. Findings indicate a necessity for including additional training diversity in the best pedagogical approaches to facilitate cross-cultural collaborative experiences in both curriculums and online education environments.

Keywords: collaboration, curriculum development, diversity, educational technology, multiculturalism, teacher training

Citation: Hali, A. U., Zhang, B., Al-Qadri, A. H., \& Aslam, S. (2021). A collaborative teacher training approach in different cultures in the era of technology. International Journal of Instruction, 14(4), 2132. https://doi.org/10.29333/iji.2021.1442a 


\section{INTRODUCTION}

In teacher education, the quest for more successful ways of teaching is a constant endeavor. Equally, the convergence of technology principles with the subject matter and educational methodology is continuous. There is also consensus that teachers, not technologies, are the forces who will bring about the desired improvement in teaching mathematics. Preparing teachers to use technologies is also a challenging problem that needs to be discussed by Clarke \& Kinuthia, 2009).

Collaborative learning allows students to engage with peers and establish intellectual relations and alternate ways of comprehension. (Laal \& Laal, 2012). Collaborative learning is unique to other group-based forms of learning, but a group component is required. Collective learning incorporates participant work generated in preparation for small group events similar to cooperative learning, which integrates individual attempts to address a broader problem. Learners may make contributions at different times or places or may do so simultaneously or location separately from other team members. An asynchronous dimension separates collective learning from similar learning approaches. (Smith \& MacGregor, 1992).

Below is a summary of five elements common to problem-based learning, cooperative learning, and collaborative learning. (Davidson \& Major, 2014, pp. 29). The sixth feature of the list is unique to collective learning only. (Smith \& MacGregor, 1992). Common assignments or learning opportunities appropriate for community work; smallgroup partnerships based on learning activities; positive, mutually beneficial actions between students when working together to perform learning tasks; individual responsibility and duty; interdependence in working together and students were working with each other but not necessarily interdependent. Thus, they will work individually, and, later on, they will work collaboratively together on their part of the work.

The community aspect of collective learning consists of collaboration and exchange of knowledge within the relationship's context and the group's solidarity and engagement. To build a group and individual success, collaboration provides a framework for students to use critical arguments. (Kolikant \& Pallack, 2015). Students must believe that success corresponds to their scores. The success of one would thereby increase the success of the others. When the interaction between groups progresses substantively and positively, students' knowledge begins to converge, and a shared understanding is developed. (Balasooriya, Hawkins, \& Corpo, 2010).

Collaborative learning is not a means to transfer knowledge from teacher to student, but rather to bring new concepts within their area of experience. Participants' cognitive and emotional capacity is improved in-group learning due to the scarcity of instructor support in the process; learners must turn to each other or to outside sources to overcome challenges, causing their assumptions to be understood. (Davidson \& Major, 2014). The idea that collective interactions can generate and shape knowledge is based on social constructivism. (Palincsar, 1998). Collaborative learning uses group activities to develop each student's understanding and functional knowledge in the long term (Barkley et al., 2014). Also, during their experience, students are expected to observe, 
interpret, produce, and apply information, which also enhances their higher-level cognitive skills and abilities for critical thought. As a result, individual success demands constructive commitment and commitment. (Laal \& Laal, 2012).

Many universities worldwide have also implemented mobile technology and are preparing to integrate them into many of the courses they deliver. This offers its pupils a great way to get in touch with the subjects they learn. These new mobile platforms provide students with 24/7 access to content and empower them to immerse themselves in that content on their own or to communicate with teachers or colleagues through web contact types. It also provides them with a way to communicate with the information in ways that were not historically available, such as touch and voice recognition technology. (Ferreira, J.B. et al., 2013).

These are some of the widely used mobile learning methods - research-based learning, context-based mobile learning, synchronous sharing, MindTools, project-based learning, and peer assessment - used in skills training and basic knowledge comprehension. Simultaneously, a few have been successful in their efforts to foster higher-order thinking skills for learners, such as problem-solving or critical thinking. (Chang, C-Y. et al., 2017).

In Pakistan, several universities have capitalized on their 'online presence to expand their student enrollment andlment and achieve diversity in their curriculum content. The Allama Iqbal Open University (http://www.aiou.edu.pk/) offers online courses and degrees using the available educational technology that the university can like live media (Aslam \& Rao, 2017). It was their Department of Computer Science (DCS), which started the E-learning activities in 1999 and gave birth to the idea of an Open Learning Institute of Virtual Education (OLIVE). What followed was the establishment of the needed infrastructure and facilities required for E-learning. A Learning Management System (LMS) allowed online classes at their main campus, the Lahore region, and other places. Relatively low-cost e-learning, fast communication methods, and automatic success assessment systems have made it a typical alternative among students who cannot attend university and opt for online education.

There is also the Virtual University of Pakistan (http://www.vp.edu.pk ), which utilizes a mix of reading materials, video lectures, online interactions (e-classrooms), and audio and video tutorials passing on knowledge. Like any typical higher education institution (HEI), they also established a strict appraisal and interpretation method. This system is being used in more than 170 campuses across Pakistan, and its broad reach gives its students a perfect chance to join in their academic activities. Furthermore, the students enrolled in it are given more flexibility than those enrolled in the university system. Hali et al. (2020) also describe a study about the teacher education system in Pakistan and recommended several aspects to improve teacher education quality.

Types of instructional designs have also been shown to affect students' mobile learning outcomes. It is also worth exploring the developments in library usage to promote mobile learning in the implementation of sensing technology and learning strategies (Tu Y-F. \& Hwang, G-J., 2018). 
Present educational needs regularly pose major obstacles to educators and have a significant effect on the physical and social climate in which they function. The task of creating learning opportunities to empower researchers and professionals with the expertise and skills they require in their practice is both real and present. In comparison, conventional teaching methods used in higher education do not necessarily fulfill current and evolving priorities. Collaborative education is one avenue for educators to pursue the evolving preferences of initiatives that aim to incorporate technology with pedagogy. This portion of the paper discusses the literature on the pedagogical dimensions of interactive and analytical teaching techniques strengthened by technical capabilities by creating e-portfolios. (Clarke and Kinuthia, 2009)

In the face of the changes in the technology available and the increasing interest in collaborative teaching for university education students. This study added specific knowledge about the vital role of technology in education. This study guided the following three research questions.

Because of the advantages that collaborative learning can carry with it in aspects of course, content mastery, and the growth of long-term interpersonal skills, collaborative learning has been increasingly incorporated into higher education through various approaches (Gould, Gilbert, Pike \& Menzies, 2018). To promote improved application of collaborative learning methods within higher education, our study team engaged in person-driven discussions on collaborative learning activities that we had previously participated in as either a learner or a teacher. Researchers are examining the collaborative training for the purpose of detecting the way professors and students collaborate for the curriculum advancement to promoting the cross-cultural collaborative online learning based on the new technology.

\section{Research Questions}

1. How have existing online educational courses capitalized on their unique platform and educational technology to show diversity in their curriculum?

2. How collaborative teaching methods across different cultures and their similarities and differences?

3. How has educational technology helped to achieve diversity in curriculum development?

\section{METHOD}

\section{Research Design}

For this analysis, a qualitative technique was used, the case study approach. To capture the results, semi-structured interviews were used. This was used to illustrate a wider image of the methods of joint teaching between various cultures.

\section{Research Settings and Participants}

Ten members of the in-service university faculty were the participants in this research. Five were ICT teachers. Teachers of English as a foreign language were three more participants. Both became professors in education and pedagogy. Five participants were female, and five were male concerning gender. All of them have witnessed the use of technologies. 


\section{Data Collection}

Ten university faculty members were interviewed, and their interviews were recorded on the author's mobile phone one later transferred into the computer and transcribed. Each interview lasted almost 40 minutes. Once transcriptions were ready and then sent back to interviewees for confirmation (see appendix for interview guide).

\section{Data Analysis}

A three-step coding approach was used for the analyses of data. An interview guide was developed and piloted before the real data collection. Here are the questions, which the author asked the respondents during interviews:

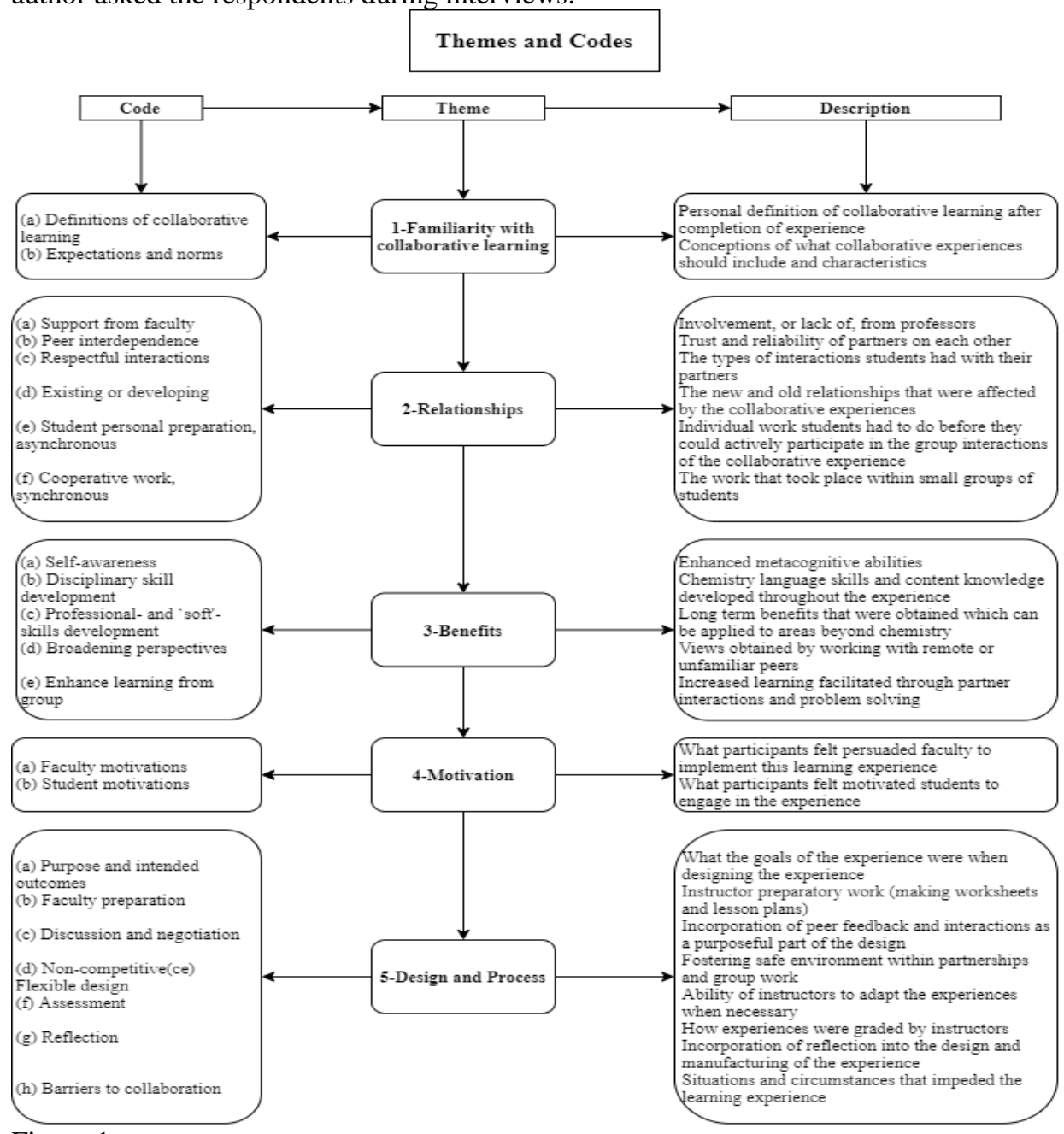

Figure 1

Coding scheme 


\section{Ethical Consideration}

A recruitment blurb was sent to twenty participants, and only ten of them accepted the invitation. During the research process, we keep the respondents' information confidential.

\section{FINDINGS}

This study was conducted to explore diversity in curriculum development through educational technology and collaborative Teacher Training in Different Cultures. The researchers, therefore, conducted class observations as students discussed methodologies of collaborative teaching across other cultures and compared the similarities and differences.

The findings show that Pakistani universities have been open to the idea of introducing online educational courses. An example of this was establishing the first digital university in the country, the University of Information Technology (ITU), which allowed Pakistani students to take courses from the world's top universities and remain at the ITU under the supervision of the ITU faculty. The respondents' example was their first-year electrical engineering students studying in circuits and electronics in the MIT course. The university leveraged technology and its university collaborations to provide its students with a mixed learning climate that centered on better learning goals by combining and implementing the best that online education can deliver in the classroom.

Another example is the Allama Iqbal Open University, which offers courses in politics, arts, literature, and the sciences. Technology must be introduced in the classrooms here in Pakistan because they are now the pen and the paper of this generation, and it is now how many students experience the world. By integrating educational technology into the curriculum of different courses of study, it stimulates the learning process of the students who, in their leisure time, choose to see the world that way as well.

This study's findings show that even at the local level, Pakistani universities have used educational technology to push for greater collaboration between local and foreign institutions. The country has capitalized on the diaspora of Pakistani intellectuals who are now based in many prestigious learning institutions abroad and have gladly collaborated with local institutions to share teacher-training expertise, among the several courses they offer.

Their goal is to achieve critical mass, reaching as many Pakistani education students who can enroll in popular online courses of some of the ' 'world's best universities. Pakistani universities have used the strategy of educational partnerships. In this way, quality education resources are shared, adapted, and customized to meet specific needs like the language used. The respondents have pointed out many initiatives to push for quality in teacher training through e-learning, seeking to promote excellence in preparing ' 'tomorrow's teachers.

Another respondent pointed out that one of the goals in teacher training online courses is to make them freely accessible to anyone, including the course materials. Today's online students are also excited about the idea and the opportunities for interaction and collaboration between their education peers from different worldwide institutions with existing partnerships. 
The assessment of how educational technology opened diversity in the curriculum development of teacher training can be seen in the strategies implemented by the different Pakistani universities, providing options for students to enter any university system level - so learning can be done on-campus distance, online and short-term provision. The respondent noted that the teaching curriculum's diversity had encouraged professors to draw on a wide range of resources in several formats. The diversity of the student population has also brought about an interest in many new fields within the realm of teacher training, which were not very popular, maybe a decade ago, so universities have introduced the teaching of the arts and literature to online courses and have developed their curriculums, as there has been an increased interest in those fields.

The following (Table1) nested case study approach was used to observe three different classes in three other universities and where they collaborated on a project on an emergency response system. The host class adopted one of the projects from the Neighbourhood of Emerging-World Technologies of the Information Technology University.

Table 1

Observation of three different classes

\begin{tabular}{|c|c|c|c|}
\hline $\begin{array}{l}\text { University } \\
\text { Name }\end{array}$ & $\begin{array}{l}\text { Educational } \\
\text { Technology Used }\end{array}$ & Curriculum Development & Collaborative Teaching Methods \\
\hline $\begin{array}{l}\text { Information } \\
\text { Technology } \\
\text { University }\end{array}$ & $\begin{array}{l}\text { Panopto - lecture } \\
\text { capture } \\
\text { application }\end{array}$ & $\begin{array}{l}\text { Applications of sensor } \\
\text { technology in one of the } \\
\text { emergency response systems } \\
\text { in ' 'Lahore's city districts }\end{array}$ & $\begin{array}{l}\text { The class helped design a circuit board } \\
\text { which was used in the emergency } \\
\text { response system } \mathrm{f}\end{array}$ \\
\hline $\begin{array}{l}\text { University of } \\
\text { California } \\
\text { Berkeley }\end{array}$ & $\begin{array}{l}\text { Panopto - lecture } \\
\text { capture } \\
\text { application }\end{array}$ & $\begin{array}{l}\text { Different configurations of } \\
\text { circuit boards that can be } \\
\text { utilized in the emergency } \\
\text { response system design }\end{array}$ & $\begin{array}{l}\text { The class showed different designs of } \\
\text { circuit boards to the students in Pakistan } \\
\text { from where they can model their project } \\
\text { for the emergency response system they } \\
\text { are designed for the city. }\end{array}$ \\
\hline $\begin{array}{l}\text { Michigan } \\
\text { Ann Arbor } \\
\text { University }\end{array}$ & $\begin{array}{l}\text { Panopto - lecture } \\
\text { capture } \\
\text { application }\end{array}$ & $\begin{array}{l}\text { A sample of an emergency } \\
\text { response system design those } \\
\text { university students designed } \\
\text { for the university and utilized } \\
\text { by them as well. }\end{array}$ & $\begin{array}{l}\text { The class presented an emergency } \\
\text { response system that they designed for } \\
\text { the university and which the students in } \\
\text { Pakistan can use for their designs. }\end{array}$ \\
\hline
\end{tabular}

\section{DISCUSSION}

Collaborative learning dialogue also relies on constructive engagement in the synchronous elements. (Laal \& Laal, 2012; Davidson \& Major, 2014). Community work alone however, does not differentiate between practice and mutual instruction. Barkley et al. (2014) argue that a particular preparatory aspect is central to the experience. Therefore, we see the minimum requirements for an individual learner to succeed in collective learning as asynchronous teaching and active engagement in the community. Our observations show that how people perceive a healthy community learning experience are more nuanced. This paper discusses the educational technologies used in the classroom to enhance students' collaborative experience, which has now expanded through the worldwide stage. As shown in Figure 2. Today's educational technologies 
have utilized information and communication technologies for practical applications in installing emergency response systems. Furthermore, ' 'today's education is now """ "'"'"virtualized"'""'"" " and has instituted digital practices in the classroom, even at the tertiary level. As shown in Figure 3, E-learning systems refer to functions in the promotion of connectivity and knowledge exchange.

The creation of Open Educational Tools (OER), the promotion of online learning processes, and the development of various pedagogical approaches that are either problem-based or project-based learning are some of the projects designed by students here in Pakistan.

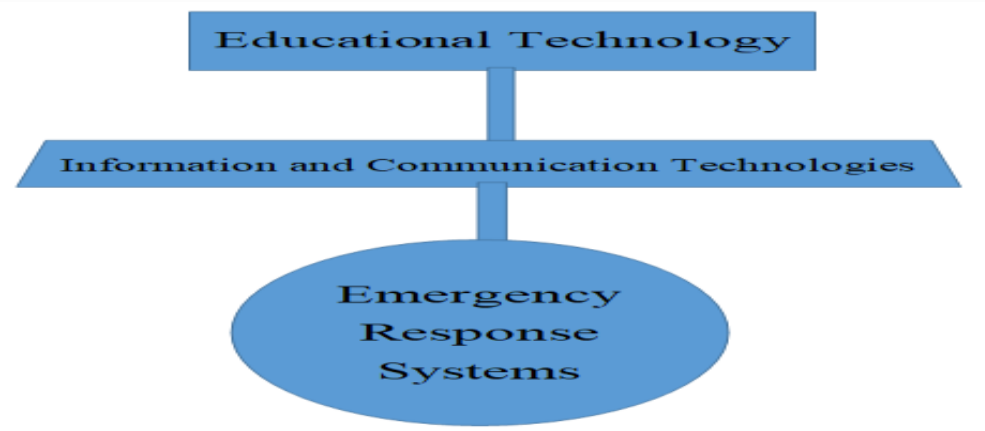

Figure 2

The uses of educational technologies filtering down to real-life applications in emergency response systems

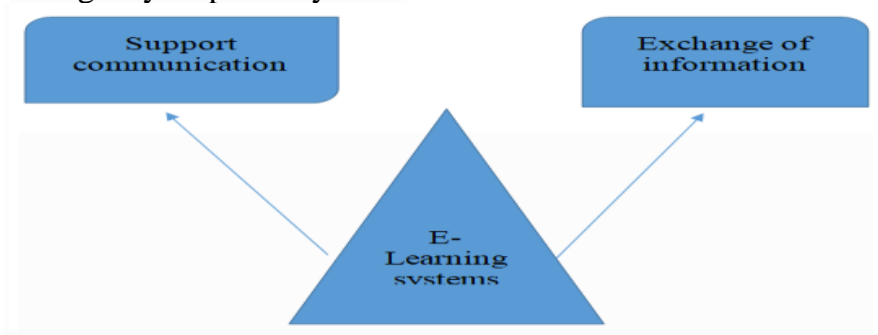

Figure 3

E-learning systems and their roles in supporting communication and exchanging information

Another educational technology being widely used today are e-Learning systems, which in the findings of the study, supported the communication process and the exchange of information during the collaborative stage of the project. Also, the creation of curriculum material at the university level as a technology-related mechanism is also stated, as it has become a repository for content teaching. Via higher education institutions, digital activities through the Internet have linked to "virtual," providing diverse educational opportunities to today's students as e-learning and hybrid learning are used. 
The concern for the quality of instruction is also mentioned. It is linked to the courses taken, the students' practices, the kind of learning environment, and the evaluation of the curriculum. The correlation between consistency and measurement is related to the design and production of materials used during the interactive session. As part of the instructional practices' design and production processes with ICT, the writers of the content, most possibly the professors, decided to position consistency and assessment. Focus is put on using technology and tools for the educational processes of teaching and training, connectivity and information, and relations between literacy, education, and universities. Social networks are among the most popular ICT tools for tertiary education institutions, but they have not been used in this study. Education, though, was included as well as the skills that bind students and teachers. In this report, the preparation of students and teachers' competencies to use the information and emerging technology is strongly emphasized.

\section{CONCLUSION}

The aim of the Pakistani educational system is to fulfil the needs of all categories of learners, the presence of educational technology makes this approach possible as it can provide a forum for curriculum creators to create demanding research courses not just for on-campus students but also for those who prefer distance learning. There has been increased interest in online courses related to teacher training whose teaching course $s$ run the whole gamut.

The study results match with the theory of online collaborative learning among a crosscultural collaborative environment, which motivates students to participate in learning and become active participants and assists students in making substantive contributions to knowledge building in an online community.

This development allows people who ordinarily would not be able to pursue teacher training the opportunity to do it even if they are busy with work or busy taking care of young children. This proves the popularity of teacher training. Distance education using educational technology can reach these students, regardless of their age and social standing, and improve their pedagogical knowledge in teacher training without leaving the pressures of their daily work or responsibilities in their home routine. The education students have used various online tools and social media and their professors to communicate and engage in peer review courses, which are obligatory to the course. There is also a need to educate online distance education course designers about the needs and aspirations of international students and international students and local Pakistani students. Educational technology has certainly opened the doors for many teacher trainee students.

In developing a cross-cultural interactive online course curriculum, science professors expressed difficulties in encouraging diverse students' involvement and contributions to knowledge building. The results also indicated that most teachers lacked pedagogical skills in developing a cross-cultural collaborative online learning framework to address the needs of various online learning classroom learners especially their ability to design 
cross-cultural collaborative learning frameworks in which online systems allow for the cultural differences of students, besides the incorporation of different tools.

\section{REFERENCES}

Aslam, S., \& Rao, C. (2017). Looking out and looking in: Exploring a case of student teachers" perceptions about the curriculum content of distance teacher education program at one general university in Pakistan. European Journal of education studies. 3(9). https://oapub.org/edu/index.php/ejes/article/view/1043

Bai, H. (2018). Preparing Teacher Education Students to use Instructional Technology in an Asynchronous Blended Course. Innovative Practices in Teacher Preparation and Graduate-Level Teacher Education Programs. North-eastern Illinois University. USA.

Balasooriya, C., Hawkins, N. J., \& Corpo, S. D. (2010). The facilitation of collaborative learning. Higher Education Management and Policy, 22, 1-14

Barkley, E. F., Cross, K. P., \& Major, C. H., (2014). Collaborative learning techniques: A handbook for college faculty (2nd ed.). San Francisco, CA: Jossey-Bass.

Beisiegel, M., et al. (2017). The Design of Video-Based Professional Development: An Exploratory Experiment Intended to Identify Effective Features. Journal of Teacher Education, 69(1). 235-243.

Benton, C. \& Falls, S. (2018). Propelling Professional Development Schools Forward: Collaborative Relationships to Revise Teacher Education Programs and Assessment Structures. Handbook of Research on Program Development and Assessment Methodologies in K-20 Education. Homer Intermediate School.

Chang, C-Y., et al. (2017). Trends and Issues of Mobile Learning Studies in Nursing Education: A Review of Academic Publications from 1971 to 2016. Computers and Education, 116, 28-48.

Clarke, P. J., \& Kinuthia, W. (2009). A Collaborative Teaching Approach: Views of a Cohort of Preservice Teachers in Mathematics and Technology Courses. International Journal of Teaching and Learning in Higher Education, 21(1), 1-12.

De Jong, D., et al. (2018). Comparative Study of Elementary and Secondary Teacher Perceptions of Mobile Technology in Classrooms. International Journal of Mobile and Blended Learning. University of South Dakota.

De Lazaro, M.L., et al. (2018). Flipped Teaching: A Useful Method for Cloud-Based GIScience Learning. Handbook of Research on Educational Design and Cloud Computing in Modern Classroom Settings. Universidad Nacional de Educacion a Distancia.

Davidson, N., \& Major, C. H. (2014). Boundary crossings: Cooperative learning, collaborative learning, and problem-based learning. Journal on Excellence in College Teaching, 25(3\&4), 7-55.

Downton, M. P. (2018). Preparation for Future Teaching: Authentic Activities in a Teacher Education Classroom. Innovative Practices in Teacher Preparation and Graduate Level Teacher Education Programs. St. ' 'John's University. 
European Commission (2014). High Level Group on the Modernisation of Higher Education: New Modes of Learning and Teaching in Higher Education.

Ferreira, J.B. et al. (2013). Mobile Learning: Definition, Uses and Challenges. Increasing Student Engagement and Retention Using Mobile Applications: Smartphones, Skype and Texting Technologies (Cutting-edge Technologies in Higher Education, Volume 6 Part D) Emerald Group Publishing Limited, pp.47 - 82 IGI Global.

Fu, Q. \& Hwang G-J. (2018). Trends in mobile technology-supported collaborative learning: A systematic review of journal publications from 2007 to 2016 . Computers \& Education, 119, 129-143.

Goyal, M., \& Krishnamurthy, R. (2018). Intuitionistic Fuzzy Logic in Student Modeling. Optimizing Student Engagement in Online Learning Environments. IGI Global.

Gould, K. S., Gilbert, A., Pike, A. J., \& Menzies, I. J. (2018). Interactive touch-screen monitors facilitate collaborative learning of microscopy skills in an introductory-level plant biology lab. Journal of Biological Education, 53, 1-7.

Hali, A. U., Zhang, B., Al-Qadri, A. H., \& Bakar, M. A. (2020). An Overview of Science Teacher Education in Pakistan. Journal of Organizational Behavior Research, 5(1), 67-74.

Kolikant, Y. B., \& Pollack, S. (2015). The dynamics of non-convergent learning with a conflicting other: Internally persuasive discourse as a framework for articulating successful collaborative learning. Cognition and Instruction, 33, 322-356.

Lamb, R.L., et al. (2018). A meta-analysis with examination of moderators of student cognition, affect, and learning outcomes while using serious educational games, serious games, and simulations. Computers in Human Behavior, 80, 158-167.

Laal, M., \& Laal, M. (2012). Collaborative learning: what is it? Procedia - Social and Behavioral Sciences, 31, 491-495. https://doi.org/10.1016/j.sbspro.2011.12.092

Laal, M., \& Ghodsi, S. M. (2012). Benefits of collaborative learning. Procedia - Social and Behavioral Sciences, 31, 486-490. https://doi.org/10.1016/j.sbspro.2011.12.091

Major, L., et al (2018). Using video to support in-service teacher professional development: the state of the field, limitations and possibilities. Journal of Online Pedagogy, 25(7). 23-34.

Marin, V., et al (2018). Thematic analysis of the international journal of educational technology in higher education (ETHE) between 2004 and 2017. International Journal of Educational Technology in Higher Education, 15(8), 123-130.

Niess, M.L. (2018). Online TPACK Learning Trajectory Tools and Processes. Teacher Training and Professional Development: Concepts, Methodologies, Tools and Applications. Oregon State University. 
Ouyang, F., et al. (2018). Adapting the TPACK Framework for Online Teaching within Higher Education. International Journal of Online Pedagogy and Course Design. University of Minnesota.

Paciga, K.A., et al., (2018). Constructing Preservice 'Teachers' Knowledge of Technology Integration. Encyclopaedia of Information Science and Technology. $4^{\text {th }}$ edition.

Palincsar, A. S. (1998). Social constructivist perspectives on teaching and learning. $\begin{array}{llll}\text { Annual Review } & \text { Psychology, } & 49(1), & 345-375 .\end{array}$ https://doi.org/10.1146/annurev.psych.49.1.345

Smith, B. L., \& MacGregor, J. T. (1992). What is collaborative learning? In A.Goodsell, M. Maher, \& V. Tinto (Eds.), Collaborative learning: A sourcebook for higher education. (pp. 1-11). Pennsylvania State University, PA. National Center on Postsecondary Teaching, Learning, and Assessment.

Tu, Y-F. \& Hwang, G-J., (2018). The Role of Sensing Technologies and Learning Strategies in Library-Associated Mobile Learning: A Review of 2007-2016. Inderscience Online, 12(1), 42-54.

Zhang, Z. \& Kenny, R. (2010). Learning in an Online Distance Education Course: Experience of Three International Students. The International Review of Research in Open and Distributed Learning, 11(1), 17-36.

\footnotetext{
APPENDIX

Semi-structured interview Questions:

1. How does collaborative learning describe you?

2. In terms of collective learning, how do you describe success?

3. What are the main characteristics of an excellent collaborative learning process?

4. In your classroom, what are your reasons for using collective learning?

5. What features make this particular experience of group learning successful (or not prosperous)?

6. In this instance, how do you assign and organize groups? How has this affected the success of the experience of collaborative learning?

7. Do you use group learning, speaking more broadly, to grasp content or facilitate soft skills growth? Will one of these inspire you more than it inspires the other?

8. If you had another university professor contact you and ask you for advice on collaborative learning, what would you recommend?

9. Why is online education in Pakistan popular?

10. How diverse are online educational offerings?

11. Do you think there are standard or hated educational offerings?

12. How many questions are there with any one of them?

13. What has the online portal led to the rise in distance education for enrolees?

14. Describe in class your collaborative interactions. From that experience, what have you learned?

15. What were the problems during your interactive learning class that occurred?

16. Has the forum for educational technologies become useful?

17. In your interactive learning, what did you learn from other cultures?

18. In today's curriculum, what do you find most relevant? Only quote an example.

19. Can you think it unrelated to any of the curriculum? Why are you thinking like that?

20. What should have been enhanced?
} 